\title{
COMPLIANCE WITH COMPLETE FILLING OF PATIENT'S MEDICAL RECORD AT HOSPITAL: A SYSTEMATIC REVIEW
}

\author{
Chrismatovanie Gloria, Pujiyanto
}

Universitas Indonesia

\begin{abstract}
Background: The health information system, especially medical records in hospitals must be carried out accurately and completely. Medical records are important as evidence for the courts, education, research, and policy makers. This study aimed to investigate the factors affecting the compliance with completeness of filling patient's medical records at hospitals.

Subjects and Methods: A systematic review was conducted by searching from ProQuest, Scopus, and National journals using keywords medical records, filling of medical records, and non- compliance filling medical records. The abstracts and full-text articles published between 2014 to 2019 were selected for this review. A total of 62,355 articles were conducted screening of eligibility criteria. The data were reported using PRISMA flow chart.

Results: Eleven articles consisting of eight articles using observational studies and three articles using experimental studies met the eligible criteria. There were two articles analyzed systematically from the United States and India, two articles reviewed literature from the United States and England, and seven articles were analyzed statistically from Indonesia, America, Australia, and Europe. Six articles showed the significant results of the factors affecting non-compliance on the medical records filling at the Hospitals.

Conclusion: Non-compliance with medical record filling was found in the hospitals under study. Health professionals are suggested to fill out the medical record completely. The hospital should enforce compliance with complete medical record filling by health professionals.
\end{abstract}

Keywords: medical record, compliance, hospital

\section{CORRESPONDENCE:}

Chrismatovanie Gloria. Hospital Administration Department, Faculty Of Public Health, Universitas Indonesia, Depok, West Java. Email: chrismatovaniegloria@gmail.com. Mobile: $+6281321161896$

The $7^{\text {th }}$ International Conference on Public Health Solo, Indonesia, November 18-19, 2020 | 344 https://doi.org/10.26911/the7thicph.04.29 